\title{
FEIRAS DE CIÊNCIA, A REVOLUÇÃO CIENTÍFICA NA ESCOLA
}

SCIENCE FAIRS, THE SCIENTIFIC REVOLUTION IN SCHOOL

FERIAS DE CIENCIA, LA REVOLUCIÓN CIENTÍFICA EN LA ESCUELA

\author{
ANTONIO CARLOS PAVÃO \\ Espaço Ciência, Olinda, PE \\ MARIA EDITE COSTA LIMA \\ Escola Arco Íris, Recife, PE
}




\title{
Resumo
}

A Feira de Ciência é um evento marcante na vida do estudante e um atraente espaço de divulgação científica, mas também é um forte indutor de atividades autônomas de pesquisa científica e tecnológica. Integra e anima alunos, professores e famílias, promovendo uma educação para a ciência onde a apropriação do conhecimento ocorre através da investigação científica em busca de soluções para problemas do cotidiano ou de interesse mais geral.

Palavras-chave: Feira de ciência. Educação científica. Divulgação científica

\begin{abstract}
The Science Fair is a remarkable event in the student's life and an attractive space for science communication, but it is also a powerful promoter of autonomous scientific and technological research activities. Integrates and encourages students, teachers and families, leading to a science education where appropriation of knowledge occurs through scientific research in searching solutions to everyday problems or of more general interest.
\end{abstract}

Keywords: Science fair. Science education. Science communication.

\section{Resumen}

La Feria de Ciencia es un evento notable en la vida del estudiante y un espacio atractivo para la difusión científica, pero también es un fuerte inductor de actividades autónomas de investigación científica y tecnológica. Integra y alienta a los estudiantes, maestros y familias, promoviendo una educación científica donde la apropiación del conocimiento ocurre a través de la investigación científica en busca de soluciones a problemas cotidianos o de interés más general.

Palabras clave: Feria de ciência. Educación científica. Difusión científica.

RBPG, Brasília, v.15, n. 34, 2019.

Experiências Inovadoras 


\section{FEIRA DE DESCOBERTAS}

Recentemente, cientistas brasileiros replicaram um experimento de pesquisadores chineses sobre a constatação de que a larva do Tenebrio molitor Linnaeus tem a capacidade de ingerir e degradar poliestireno expandido quando este lhe é oferecido como único elemento de dieta. Os brasileiros ampliaram a pesquisa, constatando que a larva era também capaz de ingerir e degradar sacola plástica oxibiodegradável, polietileno linear de baixa densidade, e outros tipos de poliestireno expandido, concluindo que a larva pode ser utilizada como um eficaz biodigestor de plásticos. O trabalho "Os fabulosos devoradores de matéria plástica", desenvolvido por alunos e alunas de $7^{\circ}$ ano, foi um dos 300 projetos apresentados em 2016 na Ciência Jovem $\mathrm{PE}^{1}$, uma das grandes Feiras de Ciência do país. É apenas um exemplo de conhecimento novo e útil onde a Feira de Ciência foi o palco para reconhecimento e apresentação dessa interessante produção científica. Mas, sem a Feira, o trabalho teria sido desenvolvido?

A Feira de Ciência estimula, organiza e divulga a produção científica da escola. Anima alunos, professores e famílias e, quando incorporada ao currículo, resulta numa estratégia educacional que naturalmente estimula atividades de investigação científica na escola, favorecendo o ensino de ciências "fazendo ciência" (PAVÃO, 2008). Na Feira "...alunos revelam insuspeitadas capacidades, e mestres que pareciam ausentes começam a viver os problemas dos estudantes" (REIS, 2018). Aprendem o professor, os alunos, as famílias e os visitantes, desperta crítica e criatividade, revela talentos e ainda gera novos conhecimentos e produtos. Feiras escolares, municipais, regionais, nacionais e internacionais, frequentemente apresentam notáveis descobertas que em essência não se diferenciam daquelas produzidas em reconhecidos centros de pesquisa. A exemplo de Reis (2018), que identificava nas Feiras de Ciência o potencial para determinar uma "revolução pedagógica", hoje podemos constatar os efeitos das Feiras de Ciência também como promotoras de uma verdadeira revolução científica, indutoras

\footnotetext{
1 Disponível em: 〈http://www.espacociencia.pe.gov.br/?atividade=ciencia-jovem>. Acesso em: 2 abr. 2019.
} 
de atividades de pesquisa promovida por alunos e professores em busca de soluções para problemas que identificaram e os tocaram.

\section{CIÊNCIA PARA EDUCAR}

Iniciada há apenas uns quatro séculos, a revolução científica se desenvolve até hoje. É uma revolução permanente, que ainda tem muitas tarefas a realizar, incluindo a tarefa da educação científica da população, cada vez mais urgente e necessária. É preciso ciência para desvendar segredos da natureza, ciência para soluções de problemas cotidianos, ciência para o desenvolvimento social, ciência para respostas às interrogações e conflitos da sociedade, ciência para o exercício da cidadania, ciência para libertação... e é preciso também ciência para a educação de nossos alunos, suas famílias e de toda a população. Para isso é preciso compreender as dimensões individual e social da ciência e ampliar os conceitos de educação formal e informal para definir que tipo de educação para a ciência poderá contribuir para a formação de cidadãos aptos para construir o tão desejado mundo sustentável.

A revolução científica traz no seu seio o conceito indissolúvel da produção, da divulgação e do ensino, estabelecendo que cientista, professor e divulgador são a mesma pessoa. Hoje, na universidade, essa trilogia se expressa em pesquisa, ensino e extensão. Como a afirmação científica deve ser submetida ao julgamento de uma comunidade, obrigatoriamente ela precisa ser divulgada, exposta aos pares (e ímpares) em congressos científicos, publicada em livros ou em artigos de revistas, a revolução científica passou a produzir um vasto material para a divulgação do conhecimento. A tão necessária informação científica, base do desenvolvimento tecnológico, foi se tornando acessível e sendo acumulada até constituir-se num corpo de conhecimentos para ser ensinado mais formalmente. Já no século XVII, Lèmery em suas aulas num boticário no Quartier Latin de Paris, oferecia uma síntese do conhecimento empírico da Química, tudo devidamente registrado em seu livro "Cours de Chimie" (LÈMERY, 1795), que acabou sendo utilizado no ensino por mais de um século, e onde se lê que nada será ensinado que "ne 
recevoir pour fondement que celui qui est palpable et démonstratif..."2 . Era um ensino onde o conhecimento era transmitido através de uma demonstração, uma comprovação experimental da afirmação, o fundamento da ciência moderna. Com a ampliação dos ramos de conhecimento, o ensino das ciências foi se tornando mais teórico e menos experimental, o livro didático se torna protagonista e o ensino passa a não ter mais como fundamento "apenas aquilo que é palpável e demonstrativo..."

Ao longo dos anos, o ensino de ciências assumiu diferentes perspectivas, desde uma prática conteudista, mais tradicional (século IX até 1950), passando pela reprodução do método científico e, por volta de 1970, com a divulgação das teorias construtivistas e sócio construtivistas, com o ensino baseado na resolução de problemas (CARVALHO, 2005). No Brasil, Azevedo et al (1932) recomenda a "[...] aplicação na escola, para aquisição ativa de conhecimentos, dos mesmos métodos (observação, pesquisa e experiência) que segue o espírito maduro nas investigações científicas”. Georges Charpak com o La main à la pâte e Leon Lederman com hands on, na década de 1990, são exemplos de cientistas que difundiram pelo mundo metodologias de ensino baseadas na investigação científica, experimental. No Brasil, Carlos Chagas Filho, ("é porque se pesquisa que se ensina”), Ernest Hamburger, Dietrich Schiel e Leopoldo de Meis são outros exemplos de cientistas que desenvolveram iniciativas em educação e divulgação científica, estabelecendo uma forte interação entre ciência e educação. Essas vertentes partilham algumas características e atualmente convivem no panorama do ensino de ciências. Todas apostam na iniciativa do professor para a promoção de atividades de investigação científica e daí destacam a necessidade de formação continuada de professores, devotando assim grande esforço nesses programas de formação. Dessa forma, apresentam resultados positivos, porém localizados, já que nenhuma dessas metodologias ganhou escala ou ofereceu garantias de continuidade das atividades de investigação científica na escola sem a intervenção de políticas públicas para apoio ao professor em programas de formação continuada. Há uma grande diferença entre a pesquisa nas universidades e nas escolas do ensino básico. Um

\footnotetext{
2 “não receba como fundamento apenas aquilo que é palpável e demonstrativo..."
} 
pesquisador na universidade é reconhecido e estimulado publicando o paper, mas também quando participa de congressos e encontros para divulgar e debater seu trabalho. Onde um aluno da educação básica pode apresentar e debater sobre sua produção? Sem uma estrutura para divulgar a pesquisa científica, não há estímulo à produção. A inexistência dessa estrutura de comunicação pública da produção científica e tecnológica acaba por favorecer um ensino de ciências voltado apenas à divulgação do conhecimento científico já estabelecido, onde a atividade dos alunos se resume a realizar experimentos de final fechado, com o objetivo de apenas reproduzir fatos já conhecidos. Nesse contexto, as Feiras de Ciência e a rede que acabou se formando em cidades, no país e no mundo, oferecem atraentes espaços de comunicação e debates científicos, sendo cada vez incorporadas em calendários escolares.

\section{CUMPRINDO O PROGRAMA}

A preocupação em "dar conta" do currículo tem sido um dos motivos que determinam o ensino superficial das Ciências. Sabemos que mais importante do que abordar uma grande quantidade de conteúdos é a qualidade com que são trabalhados. A questão de conteúdo e qualidade se associa ainda a outra, relativa ao tempo didático. Perrenoud (2001) no fala desse impasse posto pelo crescente acúmulo de conhecimentos na modernidade. Visto que é impossível fazer face a todas as informações, há que se optar entre um ensino superficial e meramente informativo e a escolha de conteúdos socialmente significativos que, além de proporcionarem variados conhecimentos científicos, contribuem para a formação de atitudes para o aprender, para a busca de informações, para a formação da cidadania e para uma formação científica com compromisso social. A escola, como tem se organizado atualmente, fragmenta seu tempo em disciplinas de conhecimentos desarticulados. Nesse contexto, a abordagem das Ciências é via de regra prejudicada, reduzindo-se seu tempo em detrimento de outras áreas como Língua Portuguesa e Matemática. A Feira de Ciência favorece o desenvolvimento de projetos interdisciplinares, com leitura da realidade, contextualização, apropriação de conceitos em diferentes áreas do conhecimento, 
cálculos, pesquisa e produção textual, desenvolvimento de habilidades e atitudes. Mesmo trabalhando um tema específico, ele se conecta com outros mais gerais. É como um novelo. O conteúdo previsto no currículo acaba se revelando durante a pesquisa para a Feira, indo além do que foi planejado. Assim, só há ganhos quando se realiza uma Feira de Ciência.

\section{DESPRIVATIZAR A ESCOLA}

Todos reconhecem a necessidade da participação da família no processo de ensino-aprendizagem. Mas quando a escola oferece oportunidades para essa participação? A Feira é esse momento oportuno. É um dos poucos momentos onde vemos as famílias no ambiente escolar. Elas querem ver o que seus filhos produziram, inclusive porque elas também participaram e acompanharam o desenvolvimento do projeto. O momento da Feira, em particular, é especial. Os concorridos debates na frente dos stands, a empolgação nas apresentações e as trocas características fazem da Feira uma experiência prazerosa, produtiva e inesquecível para participantes e visitantes. Normalmente a escola é frequentada apenas por alunos e professores. A Feira é uma forma de "desprivatizar" a escola, que se abre para famílias e outras pessoas, reafirmando seu papel social de instrumento amplificador de conhecimentos (LIMA, 2008).

As Feiras de Ciência, se bem encaminhadas e devidamente inseridas no currículo, podem favorecer forte intervenção social nas comunidades. Através delas os estudantes vão ao mundo investigando, indagando, observando, consultando fontes vivas, memórias do bairro, moradores, organizações, universidades, bibliotecas, computadores, colocando lado a lado saberes formais e informais, produzindo esquemas e registros de dados, checando informações e interpretando a realidade para construir novas versões, finalmente, identificando formas de comunicar, para um público real - e aí o conhecimento se redimensiona, investido de um sentimento social - o outro. Alunos e professores crescem, multiplicam-se. Agora não é mais uma classe, uma sala de aula, é o mundo, a vida, a Feira, o momento da efervescência, de saberes e perguntas, 
provocando novos olhares e desejos de aprofundar conhecimentos. É a escola cada vez mais militante, planejando uma maior intervenção social e envolvendo-se com questões de sua rua, bairro, cidade, partindo do particular para o universal, o mundo. Ao desenvolver projetos de estudos da realidade, o professor traça junto com seu grupo classe um planejamento. Através dele, o aluno participa da definição do objetivo da pesquisa e, desde esse momento, estamos diante da vivência de um método, de um procedimento científico. O que se quer saber? Qual o conhecimento acumulado sobre o fenômeno? - aí incluídos o conhecimento atual do aluno, o saber popular e o conhecimento científico. Muitas vezes tem-se a impressão de que esse movimento é possível apenas com os jovens, mas é preciso iniciar cedo, pois as bases do interesse em ciências têm origem na infância.

\section{ANO QUE VEM TEM MAIS}

E quanto aos trabalhos da Feira que não apresentam novidades, resumindo-se à simples execução de receitas já conhecidas, um trabalho que não é experimental e nem dá margem a discussão e interpretação dos resultados obtidos? Esses, muito comuns em Feiras de Ciência, têm lugar garantido e valor enquanto divulgação científica. Essa comunicação estabelece significados e determina um vivo aprendizado. A troca característica de toda Feira estabelece referências, permite comparações entre trabalhos e debate de ideias. Os projetos voltam diferentes no ano seguinte. Acontece de professores se decepcionarem, e aos alunos também, diante de experimentos "que não deram certo". Muitos deles perdem a oportunidade de prosseguir avaliando com o grupo os fatores que determinaram tais resultados. Na Feira acontecem "falhas", mas lá elas não são dispensadas, são observadas, analisadas e utilizadas para o crescimento e aperfeiçoamento das pesquisas e atividades dentro e fora da sala de aula.

$\mathrm{Na}$ Feira é recorrente o uso de materiais, reagentes e equipamentos alternativos acessíveis na escola, num trabalho de enorme criatividade. A ideia de que só é possível trabalhar o ensino de ciências em laboratórios e com instrumental caro e especializado não é sustentável. Embora sejam equipamentos importantes para análises e busca de 
informações, não representam o único caminho. Tão ou mais importante que um laboratório bem equipado é o aproveitamento e a utilização de recursos existentes, porque se apoiam na criatividade e conduta do professor e do aluno (MEYER, 2010). No desenvolvimento do projeto para a Feira, alunos e professores descobrem que temos à nossa volta todo um ambiente de pesquisa: alguns construídos pelo homem, como instalações elétricas e hidráulicas, geladeira, filtro, fogão, computador; outros naturais, como plantas e animais (dinossauros, minhocas, insetos, aves, etc.), terra, pedra, água, Sol, vento, chuva... Neste processo os próprios estudantes constroem seus equipamentos, recolhem materiais e compoem coleções, acumulando dessa forma um rico acervo que acaba sendo aproveitado para a construção continuada do laboratório na escola. Assim, o material de exposição não é descartado, alguns se tornam permanentes e até ocupam espaços mais visíveis da escola.

\section{A REVOLUÇÃO PERMANENTE}

A Feira de Ciência é muito mais que um evento. Desempenha papel decisivo na educação científica de alunos, professores e visitantes. Aproveita o potencial criativo e produtivo de crianças e jovens, valoriza o papel do professor como orientador, integra famílias e comunidades, promovendo um intenso movimento para descobrir, apresentar soluções e contribuir de forma significativa na construção de conhecimento e tecnologia a serviço de um mundo sustentável e mais confortável. Durante o desenvolvimento dos projetos para as Feiras de Ciência, se estabelece naturalmente um processo duradouro e autônomo de busca do conhecimento, onde alunos e professores se reconhecem como pesquisadores responsáveis por soluções úteis, locais ou globais, numa ponte da escola com seu mundo. Considerando que professor e aluno são parceiros na definição de um projeto de pesquisa para a Feira, cabe a ambos o levantamento de propostas sobre o objeto de estudo. Os estudantes colocam suas sugestões. Para o professor, é uma oportunidade de lançar um olhar sobre algum problema a investigar, seja na realidade mais imediata - por que surgiram tantos caracóis no bairro? Qual o estado de saúde das árvores do bairro? - ou na leitura de jornais - cidadãos que reclamam de recorrentes vazamentos de água, notícias sobre o excesso de algas em determinada praia -, seja na 
leitura de revistas científicas, identificando estudos possíveis de replicar e estratégias metodológicas ${ }^{3}$. Todos apresentam suas propostas e democraticamente definem o tema do projeto. Este primeiro olhar é um convite para ver o mundo com os olhos de um pesquisador. Partindo dessa provocação, os próximos serão os de seguir desvendando o novelo: Como? Vamos fazer? O que verificamos? Como interpretar? É biologia, química, física... ciências exatas, ciências da natureza, humanas, sociais, políticas? O resultado estará na Feira, o esperado momento da comunicação pública dessa produção, que sempre surpreende o público e orgulha a equipe. É a Feira de Ciências, "uma revolução pedagógica", como propagava J. Reis que, diante do sucesso de seu projeto de Feiras espalhadas no interior de no Estado de São Paulo, desejava "estender esse patriótico movimento aos demais Estados". Não existe um cadastro nacional completo, mas hoje há registros de Feiras escolares em todos os estados, algumas de abrangência estadual, nacional e até internacional. Mesmo sem política pública decisiva de apoio às Feiras de Ciência, elas se proliferaram, numa revolução pedagógica permanente, demonstrando que constituem respostas aos anseios de uma educação para a ciência mais qualificada, prazerosa e útil.

\section{REFERÊNCIAS}

ACADEMIA BRASILEIRA DE CIÊNCIAS (ABC). Ensinar as ciências na escola da educação infantil à quarta série. São Carlos: Centro de Divulgação Científica e Cultural (CDCC), 2005. Disponível em: <http://www.famesc.edu.br/biblioteca/biblioteca/ebooks/Ensinar\%20as\%20ci\%C3\%AA ncias\%20na\%20escola\%20\%E2\%80\%93\%20da\%20educa\%C3\%A7\%C3\%A3o\%20inf antil\%20\%C3\%A0\%20quarta\%20s\%C3\%A9rie.pdf>. Acesso em: 7 abr. 2019.

\section{AZEVEDO, Fernando et al. Manifesto dos pioneiros da educação nova (1932).}

Recife: Massangana, 2010. Disponível em: <http://www.dominiopublico.gov.br/download/texto/me4707.pdf $>$. Acesso em: 07 de out. 2019.

CARVALHO, Ana Maria Pessoa, et al. Ciências no ensino fundamental: o conhecimento físico. São Paulo: Scipione, 2005.

\footnotetext{
3 Disponível em: http://www.espacociencia.pe.gov.br/wp-content/uploads/2019/09/PROJETOSSELECIONADOS-1.pdf.>. Acesso em: 1 abr. 2019.
} 
LÈMERY, N. Cours de Chymie. Paris: Chez, 1755.

LIMA, M. E. C. Feiras de Ciências: o prazer de produzir e comunicar. In: Quanta Ciência há no Ensino de Ciências. São Carlos: UFSCar, 2008, p. 195.

MEYER, M. De corpo e alma: conversa ao pé do ouvido. In: Coleção Explorando o Ensino. v. 18, 2010, p. 77-88. Disponível em:

$<$ https://www.researchgate.net/profile/Nelma_Bossolan/publication/322958681_Invisiv eis hospedes_e bemvindos_os_microrganismos/links/5a79a26fa6fdcc4ffe912674/Invisiveis-hospedes-ebem-vindos-os-microrganismos.pdf\#page $=78>$. Acesso em: 15 jul. 2019.

PERRENOUD, P. Formando professores profissionais: Quais estratégias? Quais competências? Porto Alegre: Artmed Editora, 2001.

PAVÃO, A. C. Ensinar ciências fazendo ciência. In: Quanta Ciência há no Ensino de Ciências. São Carlos: UFSCar, 2008, p. 15-24.

REIS, J. Feiras de ciência: Uma revolução pedagógica (1965). In: Reflexões sobre a divulgação científica. Rio de Janeiro: Fiocruz/COC, 2018, p. 131.

Recebido: 07 de outubro de 2019.

Aprovado: 31 de outubro de 2019. 